\title{
ENTREVISTA A LIBER SEREGNI
}

\author{
Por P. Narbondo
}

Esta entrevista fue realizada en noviembre de 1992 con ocasión de la estancia en Madrid del Gral. Liber Seregni para participar en una mesa redonda sobre el futuro de la izquierda latinoamericana, organizada por la Fundación Pablo Iglesias.

Como militar ocupó cargos de alta responsabilidad, siendo de destacar la comandancia de la región número 1 del ejército. Presidente del Frente Amplio desde su fundación en 1971 fue candidato por esta fuerza política en las elecciones de 1971 y 1989. Encarcelado durante el periódo dictatorial no pudo ser candidato presidencial en las primeras elecciones de la transición debido a la proscripción, impuesta por los militares, que pesaba sobre él.

El Frente Amplio es una coalición de fuerzas de izquierda en torno a un programa común. Su aparición en la arena electoral en 1971 rompió el tradicional bipartidismo uruguayo obteniendo algo más del $18 \%$ del electorado. Duramente reprimido durante la dictadura militar, no solo ha sobrevivido, consolidándose como tercera fuerza política, sino que ha hecho serios progresos a nivel electoral, al punto que hoy por hoy aparece como una fuerza capaz de aspirar al gobierno nacional. Hay que destacar en ese avance el hecho de que en las últimas elecciones el candidato frentista a la intendencia de Montevideo, que concentra a casi la mitad de la población del país, resultó vencedor. También hay que destacar los resultados electorales a nivel nacional donde el Frente superó en las últimas elecciones el 22\% a pesar de que el PGP y el PDC se retiraron de la coalición. Todos estos datos hablan no sólo de la consolidación de la ruptura del bipartidismo tradicional en el sistema político uruguayo sino que plantea seriamente la posibilidad de que la izquierda pueda llegar a ser, en un plazo no muy lejano, una fuerza capaz de aspirar al gobierno nacional.

P: Antes de entrar en los temas específicos de Uruguay me gustaría plantearle una pregunta general sobre el sentido que tiene para usted ser de izquierda después del derrumbe de los países del llamado socialismo real. ¿Piensa que a partir de esto, el rol de la izquierda se limita a luchar por reformas dentro del sistema capitalista, intentando moderar los excesos de éste, o cree que todavía la izquierda debe y puede actuar en función de construir un sistema social distinto al capitalismo?
R: Bueno se trata de una pregunta muy amplia que concierne distintos aspectos. Yo diría que el derrumbe de los llamados países del socialismo real ha creado una tremenda confusión en los defensores del marxismo leninismo, pero esto ha afectado también a izquierdas y derechas. Esta es, entonces, la primera conclusión ya que se trata de un proceso singular de una amplitud y profundidad solo comparable con el año 17 aunque evidentemente con un sentido distinto.

En segundo lugar creo que si bien es un hecho indudable e indiscutible que la caída de esos regímenes demuestra y se debe a un fracaso del modelo, esto no quiere decir que el capitalismo haya triunfado y resuelto todos los problemas del mundo. Yo creo que en todo el mundo se está realizando un proceso de renovación a nivel ideológico. Lo cual no quiere decir tampoco que el marxismo este muerto y haya que enterrarlo, sino que está en un proceso de profundo cambio. Si tomo la referencia de América Latina y de mi país, sin lugar a dudas las ideas que llevaron a la desvertebración de los movimientos de izquierdas en el Uruguay fueron los transplantes de ideas nacidas en otras tierras y otros continentes, que tenían otras coordenadas. Recién ultimamente, - me refiero a la década del 50 - se empezó a trabajar por la renovación y la búsqueda de raíces más nacionales, y en el momento actual toda la izquierda, la no marxista pero también la marxista de todas sus versiones, desde el marxismo leninismo a ultranza pasando por todas sus variaciones, está en una revisión ideológica profunda a los efectos de situarnos en las nuevas coordenadas. En nuestro caso, es decir en el caso de Uruguay, el Frente Amplio no tiene definición marxista, ni siquiera tiene definición socialista, ya que se trata de una coalición de partidos cuya atadura es político programática y no ideológica. El objetivo en el momento actual es trabajar por un cambio dentro del sistema, pero un cambio profundo. No se trata entonces de operar dentro del capitalismo sino de avanzar hacia sistemas mixtos, lo cual implica profundos cambios. A mi me parece que hay un error que debe ser explicitado de manera clara: ante el derrumbe de las democracias socialistas del este la única alternativa es el capitalismo. El razonamiento no puede ser tan simple como eso.

P: ¿Pero entonces Ud. piensa que el horizonte de la izquierda, su objetivo sería algo así como el modelo sueco? 
R: No, puede haber formas más avanzadas que el modelo sueco, porque también se han venido dando muestras de sus limitaciones. Si bien el modelo sueco es un gran avance, tiene limitaciones que corresponden a las necesidades y realidades de la Europa del Norte, pero que no son válidas para nosotros. En ese sentido entiendo que la izquierda latinoamericana y uruguaya, incluso en sus versiones marxistas, o es profundamente nacional o no es nada.

P: Pasando al caso de Uruguay: ¿cree que es factible el triunfo a nivel nacional del Frente Amplio en las próximas elecciones?

R: Yo diría que la posibilidad del triunfo del Frente es algo concreto. Más exactamente yo diría que se trata de una severa opción de gobierno para el año 94 y que existe una muy alta probabilidad de que alcance el gobierno nacional antes de fin de siglo. No hay certezas en las ciencias sociales, por eso somos una severa opción en el 94 y una alta probabilidad en el 99.

P: Sin embargo existe un margen de votos importantes entre el $22 \%$ de las últimas elecciones y lo que sería necesario para ganar. ¿La política de alianzas definida en el último congreso sería la vía elegida para superar este margen?

R: Por supuesto que nuestra ambición sería llegar en el 94 a superar la meta del $50 \%$, pero no se trata sólo de alcanzar el gobierno. Hemos discutido este punto en nuestro Segundo Congreso (Septiembre 1991). Nosotros queremos cambiar profundamente el país su estructura política y económica, y somos conscientes de que estos cambios sólo serán posibles si son comprendidos, compartidos y participados por las mayorías nacionales. De esto se deriva en el campo político una precisión para nosotros: puesto que los procesos de los pueblos sólo son valederos y trascendentes cuando son realizados por la mayoría sensible de una nación es necesario que el Frente se encamine hacia un gobierno de mayorías y esto supone acuerdos y alianzas con fuerzas políticas, pero también y fundamentalmente con organizaciones sociales. Creo que la época que estamos viviendo se caracteriza por la importancia cada vez mayor que están adquiriendo las organizaciones sociales. No es un decrecimiento de lo político, sino un crecimiento de lo social.

El objetivo entonces es un gobierno de mayorías a través de una política de alianzas a nivel político y social. Para lo cual será necesario también realizar reformas en la Constitución y en la Ley Electoral, que haga posible los gobiernos de mayorías.

P: ¿Cual es la posición del Frente con respecto a la reforma del sistema electoral y con respecto a la reforma del régimen de gobierno?

R: Nosotros preconizamos una parlamentarización del régimen. No buscamos un régimen parlamentario puro sino que queremos encontrar un equilibrio mayor entre los poderes legislativo y ejecutivo, disminuyendo el caracter profundamente presidencialista que tiene nuestra Constitución del 66. Queremos ampliar los mecanismos de participación y desarrollar los mecanismos de defensa del ciudadano frente al Estado. Recogeríamos, por ejemplo, la figura del defensor del pueblo.

En cuanto al tema de la reforma electoral nosotros propugnamos un gobierno de mayorías. Desde este punto de vista somos defensores de la proporcionalidad que fue una gran conquista de nuestro sistema. En ese plano hay un conflicto dentro del partido nacional que fue siempre un luchador incansable de la proporcionalidad y ahora tiene dudas metafísicas y hamletianas.

P: ¿Cree que la actual organización del Frente, con la diversidad de partidos y organizaciones que conviven en él, es apta para gobernar?. ¿Que opina de la proposición del secretario general del PCU de formar un gran partido, por la unificación de diversos partidos o grupos políticos, capaz de hegemonizar el Frente?.

R: La primera cosa es la porfiada realidad. No obstante la diversidad imperante dentro del Frente, no obstante las diferencias que aparecen en el tratamiento de los problemas cotidianos, lo cierto es que el Frente como Frente ha tomado posición, y lo ha hecho a tiempo, sobre los principales problemas que se han presentado. Para esto hemos utilizado procedimientos internos de discusión basados en la democracia y en el compromiso político que finalmente establece que lo resuelto por mayoría es de cumplimiento obligatorio para todos.

En cuanto a la propuesta de Jaime Pérez hay que tener en cuenta que el Frente nació como una coalición y ha logrado una importante consolidación perdurando a través de 11 años de dictadura. Se ha formado entonces una mistica propiamente frentista que perdura a través de los años. Hay gente que dice hagamos el partido del Frente Amplio, pero no creo que ese partido tuviera la capacidad del Frente para aglutinar voluntades y militancia. Por lo tanto creo que la propuesta de J. Pérez corresponde al problema de la crisis ideológica que se le plantea a su partido. Puede ser que la formación de ese partido sea deseable en un futuro. Pero ahora no sería el momento, creo que una presencia hegemónica dentro del Frente le restaría amplitud.

P: ¿Cual es la relación actual del Frente Amplio con los militares?. ¿Que objetivos se propone el Frente en esta relación?

R: Desde el 84, que participamos en la recomposición democrática, planteamos una sociedad que quiere vivir en democracia y por sobre todas las cosas en paz. Partimos de una realidad que es la fractura entre fuerzas militares y sociedad civil, preconizamos desde el primer momento un orden de acercamiento entre ambos. No se ha logrado en plenitud y es un capítulo en el cual tenemos programado y escrito bastante. Queremos unas fuerzas armadas al servicio del país que cultiven la auténtica defensa de la soberanía nacional desde una concepción lationamericana, participando en el proceso de desarrollo que el país tiene que tener, pero absolutamente subordinadas al poder civil. En este proceso nadie tiene que quedar aparte y tampoco las fuerzas armadas, que por su organicidad y competencia 
técnica son elementos que también tienen que intervenir en el proceso.

P: Esto conlleva un proceso de relación del Frente con las fuerzas armadas, es decir un proceso de discusión...

R: No, discusión del Frente con las fuerzas armadas no. Relaciones por supuesto pero dentro del marco constitucional.

P: ¿Piensa que ha habido evolución en las posiciones de las fuerzas armadas con respecto al Frente Amplio?

R: Si, y con una referencia específica: el compromiso de las fuerzas armadas de acatar la decisión soberana del pueblo.

P: Pasando al aspecto económico del programa del Frente Amplio, ¿cree que es posible, en el momento histórico que vivimos, un programa económico que sea aplicable y que al mismo tiempo sea especificamente de izquierda? o dicho de otra manera, ¿es posible aplicar un programa económico distinto al que se esta aplicando en América Latina hoy por hoy?

R: Es posible y vitalmente necesario para el futuro. Admitir la imposibilidad sería admitir el suicidio de la izquierda. Nuestra propuesta alternativa es el enfrentamiento a la política neoliberal y a sus resultados oponiendo a esto un programa de economía social.

P: ¿Cual es la posición del Frente con respecto al problema del rol del Estado en la economía?

R: No tenemos una propuesta alternativa total y absolutamente definida, porque si queremos que esa propuesta sea compartida y participada por la mayoría hemos de discutirla partiendo de una base amplia de negociación y acuerdo. Ahora bien, creemos que el rol del Estado debe ser el de orientador de la vida política y económica del país, porque su función es insustituible en un mundo caracterizado por la incertidumbre. Lo que se nos propone es dejar que el mercado determine la prioridades y que asigne los recursos. Pero yo me pregunto: ¿donde está el mercado libre? No existe en ningún lado y la realidad es que está manejado por intereses de otros Estados y, por sobre todas las cosas, por intereses de las trasnacionales. Nosotros entendemos que el Estado debe intervenir en la economía sentándose en una mesa con los empresarios nacionales, fijándoles los grandes objetivos que hay que alcanzar y discutiendo a nivel de las fuerzas económicas la suerte de los trabajadores y el conjunto social articulado. No se trata de un Estado omnipotente pero si de un Estado que participe y oriente el proceso de decisión sobre la economía.

Una de las cosas fundamentales que nosotros queremos cambiar es el funcionamiento del sistema financiero. Se está privilegiando al sector financiero por encima de cualquier otra consideración y se especula financieramente. Nosotros queremos poner los recursos al servicio de la producción como condición absolutamente imprescindible para desarrollar el país. Esto supone una intervención fuerte del Estado en el sistema financiero. Para esto se trata de utilizar los recursos que tiene el Estado actualmente, es decir el Banco Central, el Banco República y los bancos actualmente en poder del Estado.

Pero hay otras áreas económicas que afectan la seguridad del país. Cuando hablamos de soberanía me refiero a las áreas que nosotros llamamos estratégicas: los combustibles, la energía, las comunicaciones. A ese nivel no es que el Estado vaya a seguir estatizando, incluso en las empresas estatales actuales admitimos la participación del capital privado. Pero lo que yo no puedo admitir es que Antel, que es una compañía que da ganancias, se venda y el Estado quede minoritario. No encuentro razón para eso.

P: Para terminar, me gustaría preguntarle si considera que el objetivo de abolir la propiedad capitalista de los medios de producción y dar acceso a esta a los trabajadores sigue siendo un objetivo o si, por el contrario, piensa que este objetivo ha desaparecido del horizonte programático de la izquierda?

R: Lo que ha habido es un cambio sensible en los planteamientos. Concretamente han habido cambios profundos en las relaciones de producción y consecuente conformación y relaciones entre las clases. La característica de clase está dada en función de los medios, y las modificaciones impresas por el avance científico son tremendas y han desvalorizado ciertos aspectos. No importa tanto la propiedad en si, sino que lo más importante es la gestión y la administración. Este factor es fundamental. Yo lo diría con un ejemplo: a nivel de la tierra y de la reforma agraria el esquema fue siempre la propiedad de la tierra, la parcela, y ahora este es un factor absolutamente secundario con respecto a la gestión productiva en si. Esos cambios son ciertos. Además lo que importa no es la propiedad, lo que importa es el goce y el usufructo de lo producido. Ese es el eje fundamental y marca la necesidad de la puesta en práctica de principios de cogestión a nivel de empresa. Y eso se va produciendo. Por supuesto existe el capital privado, pero este empieza a ser de más en más coparticipado, la propia dinámica del proceso lo va haciendo. Por eso digo que nuestro enfasis es para dar a la empresa privada características de administración colectiva para generar la propiedad social. La cogestión como un elemento sustantivo y sustancial cuando está bien hecha significa que tanto el patrón como los empleados participan activamente. 